INFLAMMATION of the rat distal intestine was induced by intradermal sensitization and subsequent multiple intrajejunal challenge with the hapten 2,4,6-trinitrobenzenesulphonic acid (TNBS) via an implanted catheter. The time course of the inflammatory reaction was followed by determination of the enteritis score and measurement of in vitro eicosanoid formation of homogenates of the gut after $0,1,2,4,7,14$ and 21 days of local daily challenge with $0.08 \%$ TNBS. There was a small initial increase of eicosanoid formation, reached at days 1 and 2, followed by a significant increase in metabolism of arachidonic acid on day 21. Although at day 1 a four-fold increase in inflammation score was reached, no further significant changes were observed during the following 3 weeks. The greatest increase in metabolite formation was observed in prostanoids $\mathrm{TxB}_{2}, \mathrm{PGE}_{2}$ and $\mathrm{PGD}_{2}$ and the 5-lipoxygenase product $\mathrm{LTC}_{4}$, whereas minor changes were found for $\mathrm{LTB}_{4}$ and other lipoxygenase products such as 12 - and 15-HETE. The formation of these metabolites was already inhibited by low-dose 5-aminosalicylic acid (5-ASA), given orally twice daily during the 3 weeks challenge period, while the enteritis score was affected dosedependently.

Key words: Arachidonic acid metabolism, 5-ASA, Chronic immunologic enteritis

\section{Arachidonic acid metabolism in TNS-induced chronic and immunologic enteritis in rats, and the effect of 5-ASA}

\author{
F. J. Zijlstra, ${ }^{1, C A}$ A. P. M. van Dijk, ${ }^{1}$ \\ N. Selve ${ }^{2}$ and J. H. P. Wilson ${ }^{3}$
}

${ }^{1}$ Department of Pharmacology, Erasmus University, Rotterdam, the Netherlands; ${ }^{2}$ Department of Pharmacology, Grünenthal $\mathrm{GmbH}$, Aachen, Germany;

${ }^{3}$ Department of Internal Medicine II, University

Hospital Dijkzigt, Rotterdam, the Netherlands

${ }^{\mathrm{CA}}$ Corresponding Author

\section{Introduction}

Ulcerative colitis and Crohn's disease represent two entities of inflammatory disease of the large and small intestine whose aetiology and inter-relationships are not yet known. Their course is both acute and chronic, with unpredictable remissions and exacerbations, many local and systemic complications, and variable response to therapy. ${ }^{1}$ Progress in understanding the pathogenesis of ulcerative colitis and Crohn's disease has been hampered by the intrinsic complexity of the diseases and their variable manifestations, which serve to make the distinction between essential and non-essential features difficult. Another important limitation in the study and understanding of the diseases has been the lack of suitable animal models. ${ }^{2}$

Despite this, immunoregulation and lymphocyte function in patients with ulcerative colitis has been reported to be abnormal, suggesting that it may be an autoimmune disorder. ${ }^{3-5}$ Moreover metabolites of arachidonic acid seem to be implicated in the pathogenesis of inflammatory bowel diseases. Cyclooxygenase as well as lipoxygenase metabolites have been reported to be increased in patients with ulcerative colitis or Crohn's disease. ${ }^{6-9}$ The anti-inflammatory properties of prostaglandin $\mathrm{E}_{2}$ $\left(\mathrm{PGE}_{2}\right)$ are well described, ${ }^{10}$ in contrast to the pro-inflammatory action of leukotriene $\mathrm{B}_{4}\left(\mathrm{LTB}_{4}\right)$, whereas several eicosanoids are involved in the feed-back mechanisms of the arachidonic acid cascade. In the present study the metabolism of arachidonic acid in inflamed mucosal tissue taken from an animal model of inflammatory bowel disease (IBD) ${ }^{11}$ was investigated in order to elucidate further the involvement of arachidonic acid metabolites in inflammatory bowel disease. In a previous study, it was shown that the level of $e x$ vivo released immunoreactive $\mathrm{LTB}_{4}$ was elevated in inflamed distal small intestine taken from rats with TNBS-induced chronic enteritis. ${ }^{11}$ In the present study the balance between cyclooxygenase and lipoxygenase metabolites formed by rat distal small intestine has been investigated. Furthermore, the validity of this model was investigated by examining the effects of 5-aminosalicylic acid (5-ASA), on both the enteritis score and the ratio of pro- and anti-inflammatory products formed.

\section{Materials and Methods}

Induction of enteritis: Inflammation of the rat distal small intestine was induced by a method previously described in detail. ${ }^{11,12}$ Female rats $(150-200 \mathrm{~g})$ were sensitized by intradermal injection of $0.05 \mathrm{ml}$ of $0.8 \%$ 2,4,6-trinitrobenzenesulphonic acid (TNBS) into their back once daily for 3 consecutive days. 
After 18 days the animals received a further intradermal booster injection $(0.05 \mathrm{ml})$. After a further 10 days the animals were challenged once daily for 21 consecutive days by intrajejunal application of a $0.08 \%$ TNBS preparation $(0.2 \mathrm{mg} /$ rat) via an implanted catheter. Drug treatment with 5-ASA $(4.64,10.0,21.5$ and $46.4 \mathrm{mg} / \mathrm{kg} / \mathrm{day}$; Heraeus, Karlsruhe, Germany) was performed by oral application twice a day starting $6 \mathrm{~h}$ before the first local TNBS administration and was continued for 3 weeks, the last drug application being performed $6 \mathrm{~h}$ before the last TNBS administration. 5 -ASA was suspended in $1 \%$ carboxymethylcellulose. Each group consisted of ten rats.

Working-up method of distal small intestine: Rats were killed by $\mathrm{CO}_{2}$ asphyxiation $24 \mathrm{~h}$ after the last intraluminal application of TNBS at day $0,1,2,4$, 7,14 and 21. The distal $10 \mathrm{~cm}$ of small intestine were dissected out and immediately assessed by two independent observers for inflammation using a macroscopic enteritis score of value $0-3$, defined as no (0), slight (1), intermediate (2) or intense (3) redness of the intestine. ${ }^{11,12}$ Segments of precisely $10 \mathrm{~cm}$ were rinsed in saline and weighed as a parameter of oedema or granuloma formation. Segments of inflamed and control distal small intestine were histologically examined for qualitative confirmation of the visual assessment of inflammation.

Eicosanoid metabolism and determinations: To determine eicosanoid reduction of the inflamed mucosa, tissue samples of distal small intestine were homogenized in Krebs' buffer by means of an Ultra-Turrax, incubated for $10 \mathrm{~min}$ with $0.125 \mu \mathrm{Ci}\left[{ }^{14} \mathrm{C}\right]-$ arachidonic acid and stimulated with $\mathrm{Ca}$-ionophore A23187 $(2 \mu \mathrm{M}) .{ }^{9}$ The ${ }^{14} \mathrm{C}$-labelled eicosanoids formed were separated by HPLC and measured by on-line beta detection. ${ }^{13}$ Total protein content of any tissue sample was determined. ${ }^{14}$

Data handling: Data obtained by comparison of enteritis score, gut weight, protein content and formation of arachidonic acid metabolites, expressed as mean \pm S.E.M. of ten experiments per group, were statistically analysed by MannWhitney $U$-test; values of $p \leq 0.05$ being considered as significant.

\section{Results}

Enteritis score: A rapid increase of the enteritis score was observed from day 0 to day 2, which did not further increase until day 21 of daily intrajejunal treatment with TNBS (Table 1). Histological examination of the gut samples confirmed the results obtained by macroscopic enteritis score. Remarkable changes in mucosal
Table 1. Enteritis score before and several times after local TNBS administration and 5-ASA treatment $(n=10)$

\begin{tabular}{cc}
\hline Days after TNBS & Enteritis score \\
\hline 0 & $0.5 \pm 0.02$ \\
1 & $2.1 \pm 0.10$ \\
2 & $2.2 \pm 0.08$ \\
4 & $2.1 \pm 0.06$ \\
7 & $1.9 \pm 0.11$ \\
14 & $2.0 \pm 0.06$ \\
21 & $2.3 \pm 0.08$ \\
\hline $5-$ ASA (mg/kg) & \\
after 21 days TNBS & Enteritis score \\
\hline 4.64 & $1.7 \pm 0.12^{*}$ \\
10.0 & $1.6 \pm 0.13^{*}$ \\
21.5 & $1.2 \pm 0.12^{*}$ \\
46.4 & $1.1 \pm 0.07^{*}$ \\
\hline${ }^{*} p<0.01$ vs day 21 of non-treated rats.
\end{tabular}

integrity and activation of Peyer's patches were induced. There was no significant difference between the TNBS groups from day 2 to day 14 of local TNBS treatment. Acute inflammatory response with a predominantly neutrophil infiltration was not detectable. The histology showed light to moderate signs of chronic inflammation with infiltration of mainly lymphocytes and histiocytes.

Body weight: Body weights were not significantly changed during intrajejunal implantation, TNBS challenge or 5-ASA treatment.

Gut weight: Gut weights of all $10 \mathrm{~cm}$ samples were similar during the time course of TNBS treatment within a range of 0.78 to $0.95 \mathrm{~g} / 10 \mathrm{~cm}$ distal small intestine. No significant difference was observed between the different groups (data not shown).

Protein content: Protein content of all tissue samples taken from distal small intestine after different times of intrajejunal TNBS treatment was constant within a range of 11.8 to $14.2 \mu \mathrm{g} / \mathrm{mg}$ tissue and no significant differences were observed between the different groups (data not shown).

Arachidonic acd metabolite profile: The main results in determination of the time course of arachidonic acid metabolism were: (1) a slight increase of overall eicosanoid production after 1 day of TNBS treatment; (2) no change of metabolism after 1 to 14 days of intrajejunal TNBS treatment; and (3) a marked increase of eicosanoids after 21 days of TNBS treatment.

The greatest increase of eicosanoids was observed in the formation of $\mathrm{TxB}_{2}, \mathrm{PGD}_{2}$ and sulphidopeptide leukotrienes (S-LTs) (25-30-fold compared to controls, Figs 1, 2 and 3). Smaller increases were found for the $\mathrm{PGE}_{2}$ (10-fold), $6_{\mathrm{kPGF}}{ }_{1 \alpha}, \mathrm{LTB}_{4}$, 12- and 15-HETE (5-fold 


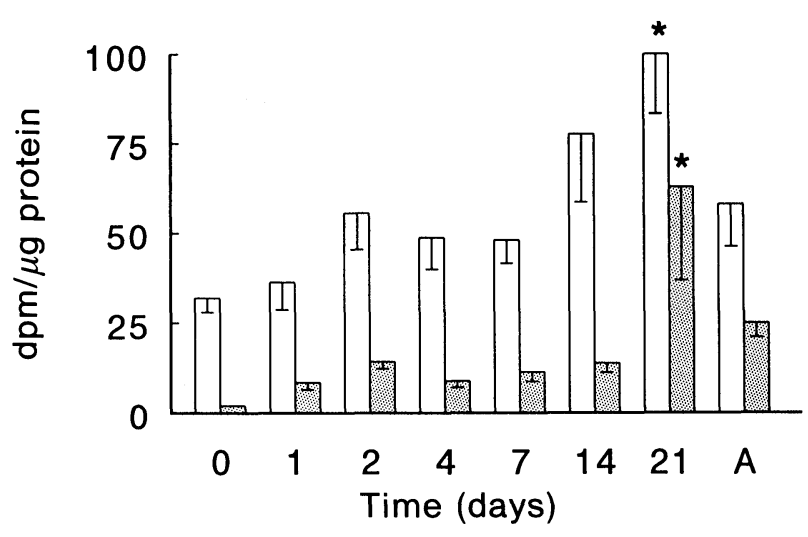

FIG. 1. Production of $\left[{ }^{14} \mathrm{C}\right]$-arachidonic acid derived cyclooxygenase metabolites $6 \mathrm{KPGF}_{1 \alpha}$ and $\mathrm{TxB}_{2}$ (expressed as dpm/ $\mu \mathrm{g}$ protein) by distal small intestine homogenates of rats treated with local TNBS for different time periods $(0,1,2,4,7,14$ and 21 days) and (pre)treated with 5-ASA $(4.64 \mathrm{mg} / \mathrm{kg} / \mathrm{day})$ after local TNBS for 21 days $(\mathrm{A}) . n=10 ;{ }^{*} p<0.05 \mathrm{vs}$ $t=0 . \square, 6 \mathrm{kPGF}_{1 \alpha} ;$ 圈, $\mathrm{TxB}_{2}$

increase; Figs 1-4). No changes were observed in HHT, 5-HETE, and 8-HETE formation (data not shown).

Effects of 5-ASA: Oral treatment of the animals with 5-ASA dose-dependently reduced the enteritis score after 21 days of intraluminal application of TNBS (Table 1). Gut weight of distal small intestine of a defined length of $10 \mathrm{~cm}$ was slightly reduced by 5-ASA treatment. Both the increased cyclooxygenase and lipoxygenase production after 21 days of TNBS application was diminished to $40 \%$ of the production by 5 -ASA treatment (see Figs 1-4, A-marked bars) still being a 2-4-fold increase compared to control values on day 0 .

\section{Discussion}

In this study the authors found an increase in the metabolism of arachidonic acid by homogenates of inflamed distal small intestine taken from rats

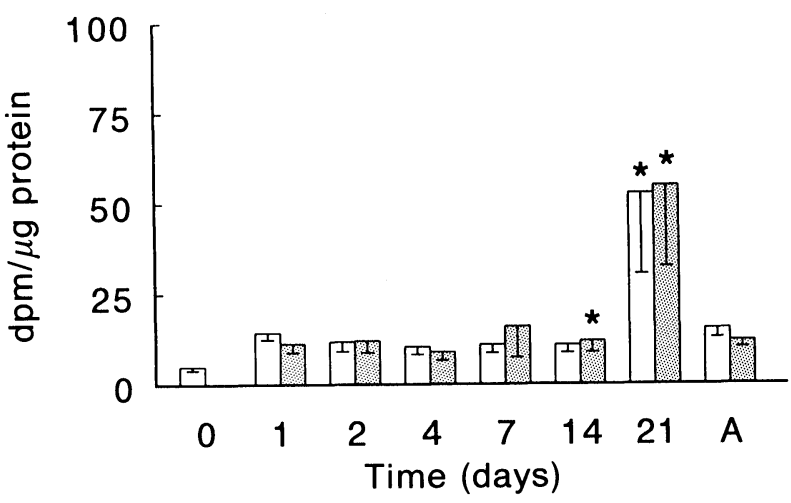

FIG. 2. Production of $\left[{ }^{14} \mathrm{C}\right]$-arachidonic acid derived cyclooxygenase metabolites $\mathrm{PGE}_{2}$ and $\mathrm{PGD}_{2}$ (expressed as dpm/ $\mu \mathrm{g}$ protein) by distal small intestine homogenates of rats treated with local TNBS for different time periods $(0,1,2,4,7,14$ and 21 days) and (pre)treated with 5-ASA (4.64 mg/kg/day) after local TNBS for 21 days (A). $n=10 ;{ }^{*} p<0.05$ vs $t=0 . \square, \mathrm{PGE}_{2}$; 圈, $\mathrm{PGD}_{2}$.

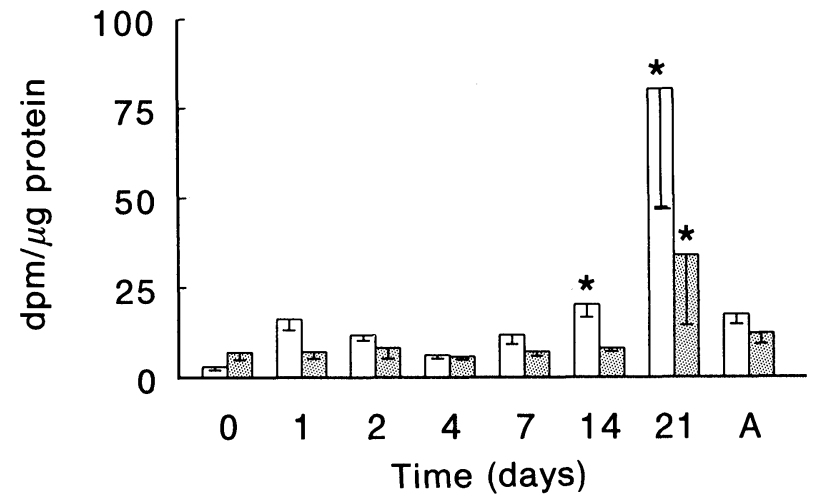

FIG. 3. Production of $\left[{ }^{14} \mathrm{C}\right]$-arachidonic acid derived 5-lipoxygenase metabolites sulphidopeptide LTs (S-LTs $\left.=\mathrm{LTC}_{4}+\mathrm{LTD}_{4}\right)$ and $\mathrm{LTB}_{4}$ (expressed as $\mathrm{dpm} / \mu \mathrm{g}$ protein) by distal small intestine homogenates of rats treated with local TNBS for different time periods $(0,1,2,4,7,14$ and 21 days) and (pre)treated with $5-A S A(4 \mathrm{mg} / \mathrm{kg} /$ day) after local TNBS for

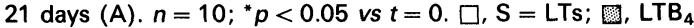

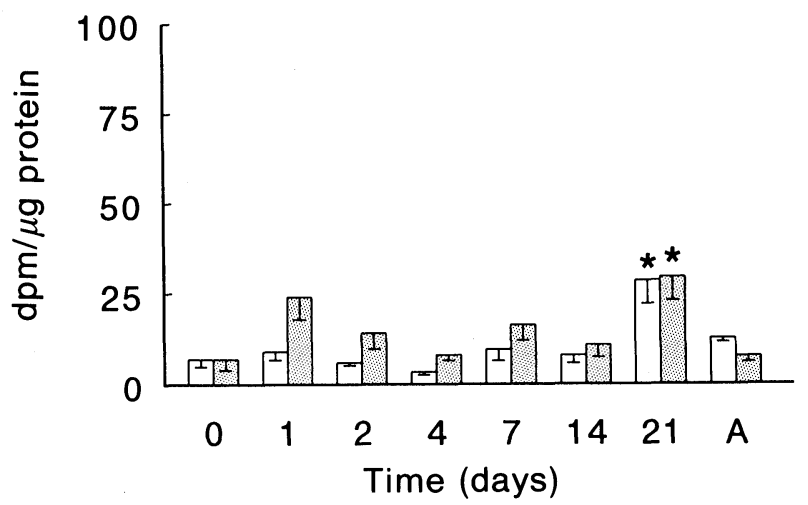

FIG. 4. Production of $\left[{ }^{14} \mathrm{C}\right]$-arachidonic acid derived 12 - and 15 lipoxygenase metabolites 12-HETE and 15-HETE (expressed as $\mathrm{dpm} / \mu \mathrm{g}$ protein) by distal small intestine homogenates of rats treated with local TNBS for different time periods $(0,1,2,4,7,14$ and 21 days) and (pre) treated with 5-ASA ( $4.64 \mathrm{mg} / \mathrm{kg} /$ day) after local TNBS for 21 days (A). $n=10 ; " p<0.05$ vs $t=0 . \square, 15-\mathrm{HETE}$; 圆, 12-HETE.

during chronic enteritis induced by the chemical hapten TNBS. In previous studies marked species differences in the production pattern of eicosanoids by inflammatory cells was shown. ${ }^{15}$ These differences also occur in inflamed and non-inflamed colonic tissue. ${ }^{16}$ In human inflammatory bowel disease mainly $\mathrm{PGE}_{2}$ and $\mathrm{LTB}_{4}$ were measured in dialysis fluid, ${ }^{17}$ whereas lately evidence was obtained that other lipoxygenase products, such as 15HETE, are important mediators of inflammation. It is known that prostacyclin and 15-HETE are formed by endothelial cells. Probably during the type of inflammation used in this study these cells are not triggered to increase eicosanoid synthesis. The prostaglandins $\mathrm{LTC}_{4}$ and $\mathrm{LTB}_{4}$ normally are formed by macrophages, eosinophils and mast cells respectively. ${ }^{18}$ Thromboxane, however, is mainly formed by platelets and macrophages. ${ }^{15}$ In human colitis $\mathrm{TXB}_{2}$ formation was not increased sig- 
nificantly in colonic mucosa, ${ }^{9}$ whereas in experimental colitis marked elevation of thromboxane synthesis was only observed in rabbits after the induction of dinitrochlorobenzene $(\mathrm{DNCB})^{8,19}$ and formyl-methionyl-leucyl-phenylalanine (FMLP). ${ }^{20}$ In acute inflammation a rapid influx of granulocytes is seen, followed by inflammatory cells such as macrophages. Although in histological sections the contribution of platelets was negligible, one should consider the potency of platelets in generating thromboxane.

Despite the variation of the different types of metabolites determined in this investigation following the time course, the results suggest a break-even point between 14 and 21 days of local intraluminal TNBS treatment. However, this does not correlate with the observed changes in enteritis score and histological assessment of the distal small intestine after different times of TNBS treatment.

According to the normal time course of inflammatory reactions an early response characterized by acute inflammation and a late response characterized by chronic inflammation were expected during the time course of TNBS treatment. This was partly supported by the small initial increase in mediators and the exacerbation of mediator production after 21 days. This observation, however, was not confirmed by histologic observations as there was no detectable infiltration of neutrophils that would indicate an acute inflammatory response. The onset of inflammation on day 2 of TNBS treatment was characterized by infiltration of lymphocytes and histiocytes, indicating chronic inflammatory response directly after TNBS treatment. These results are somewhat unexpected, and future studies should include examination of changes in the first hours of local TNBS treatment.

In contrast to other immunologically induced chronic inflammation of the gut as animal models of IBD, ${ }^{8,21-26}$ chronicity of the inflammatory reaction in this model was induced by multiple instead of one $\mathrm{e}^{21}$ or $\mathrm{few}^{22,25,26}$ local administrations of the immunogen. Another difference is a 3-week instead of 3 -day ${ }^{22,25,26}$ time schedule for the local challenge procedure. This repeated and weak stimulation of the immune system by one specific immunogen may mimic the human disease more closely, and the model has more features in common with human IBDs than non-immunological and acute models. ${ }^{27}$ In contrast to the human disease the typical discontinuous time course and the mixture of chronic and acute inflammation ${ }^{28}$ were not induced in this model.

Oral 5-ASA (low dose, $4.64 \mathrm{mg} / \mathrm{kg} /$ day) during the 21-day TNBS treatment schedule clearly reduced eicosanoid formation, but resulted in only a slight decrease of approx. $15 \%$ in histological examination and symptom score. The enteritis score, however, was dose-dependently decreased (Table 1), while a further inhibition of eicosanoid synthesis was not observed. An explanation for this could be that only a weak dose of 5-ASA is sufficient to influence AA metabolism, but that much higher doses are needed to counteract the severe signs of inflammation as was reflected in the macroscopic inflammation score. The time schedule of 5-ASA treatment in this investigation includes the whole time period of enteritis induction by local TNBS administration. In order to answer the question of whether 5-ASA is effective on early or established inflammatory response of the distal small intestine in this model, further investigations with different time schedules of 5-ASA treatment have to be performed.

In conclusion, although this model has many features of Crohn's disease, it is still not clear whether it is suitable for testing new drugs in IBD, especially those which are supposed to act as inhibitors of the arachidonic acid metabolism. These present findings indicate that eicosanoids are important mediators in the chronic phase of inflammatory bowel disease, ${ }^{29}$ probably in the regulation of the release of pro-inflammatory substances such as platelet activating factor (PAF), ${ }^{30}$ cytokines, ${ }^{31} \mathrm{LTB}_{4}{ }^{32}$ and $\mathrm{LTD}_{4} \cdot{ }^{33}$ Further investigations with the use of nonspecific acting anti-inflammatory drugs, such as corticosteroids, could give more information about this sequential release of inflammatory mediators.

\section{References}

1. Kirsner JB. Inflammatory bowel disease - what is known and what is new a 1989 overview. Scand J Gastroenterol 1989; 24: 19-20.

2. Podolsky DK. Inflammatory bowel disease. N Engl J Med 1991; 325 928-937.

3. von Herbay A, Gebbers JO, Otto HF. Immunopathology of ulcerative colitis. Hepato-Gastroenterol 1990; 37: 99-107.

4. Fiocchi C. Immune events associated with inflammatory bowel disease. Scand $J$ Gastroenterol 1990; 25: 4-12.

5. Raedler A, Schreiber S. Immunology of ulcerative colitis. Hepato-Gastroenterol 1989; 36: 213-218.

6. Schumert R, Towner J, Zipser RD. Role of eicosanoids in human and experimental colitis. Dig Dis Sci 1988; 33: 58s-64s.

7. Donowitz M. Arachidonic acid metabolites and their role in inflammatory bowel disease. Gastroenterology 1985; 88: 580-587.

8. Boughton-Smith NK, Whittle BJR. Increased metabolism of arachidonic acid in an immune model of colitis in guinea-pigs. Br J Pharmacol 1985; 86 439-446.

9. Zijlstra FJ, van Dijk APM, Wilson JHP, van Riemsdijk-Overbeeke IC, Vincent JE, Ouwendijk R JT. 15-HETE is the main eicosanoid formed by human colonic mucosa. Agents Actions 1992; 35: C53-C59.

10. Fedorak RN, Empey LR, McArthur C, Jewell LD. Misoprostol provides a colonic mucosal protective effect during acetic acid-induced colitis in rats. Gastroenterology 1990; 98: 615-625.

11. Selve N, Wöhrmann T. Intestinal inflammation in TNBS sensitized rats as a model of chronic inflammatory bowel disease. Mediators of Inflammation 1992; 1: 121-126.

12. Selve $\mathbf{N}$. Chronic intraluminal TNBS application in TNBS-sensitized rats-a new model of chronic inflammatory bowel diseases. Agents Actions 1992; 35: C15-C17.

13. Zijlstra FJ, Wilson JHP, Vermeer MA, Ouwendijk RJTh, Vincent JE. Differential effects of malotilate on 5-, 12-, and 15-lipoxygenase in human ascites cells. Eur J Pbarmacol 1989; 159: 291-295.

14. Lowry OH, Rosebrough NJ, Farr AL, Randall RJ. Protein measurement with the Folin phenol reagent. $J$ Biol Chem 1951; 193: 265-275.

15. Ouwendijk RJTh, Zijlstra FJ, van den Broek AMWC, Brouwer A, Wilson JHP, Vincent JE. Comparison of the production of eicosanoids by human 
and rat peritoneal macrophages and rat Kupffer cells. Prostaglandins 1988; 35 437-446.

16. Zijlstra FJ, van Dijk APM, Garrelds IM, Ouwendijk RJTh, Wilson JHP. Species differences in the pattern of eicosanoids produced by inflamed and non-inflamed tissue. Agents Actions 1992; 35: C73-C75.

17. Lauritsen K, Laursen LS, Bukhave K, Rask-Madsen J. Effects of topical 5-amino-salicylic acid and prednisolone on prostaglandin $\mathrm{E}_{2}$ and leukotriene $\mathrm{B}_{4}$ levels determined by equilibrium in vivo dialysis of rectum in relapsing ulcerative colitis. Gastroenterology 1986; 91: 837-844.

18. Fretland DJ, Djuric SW, Gaginella TS. Eicosanoids and inflammatory bowel disease: regulation and prospects for therapy. Prostagl Leukotr Ess Fatty Acids 1990; 41: 215-233.

19. Kao Hw, Zipser RD. Exaggerated prostaglandin production by colonic smooth muscle in rabbit colitis. Dig Dis Sci 1988; 33: 697-704.

20. LeDuc LE, Nast CC. Chemotactic peptide-induced acute colitis in rabbits. Gastroenterology 1990; 98: 929-935.

21. Morris GP, Beck PL, Herridge MS, Depew WT, Szewczuk MR, Wallace JL. Hapten-induced model of chronic inflammation and ulceration in the rat colon. Gastroenterology 1989; 96: 795-803

22. Bicks RO, Rosenberg EW. A chronic delayed hypersensitivity reaction in the guinea-pig colon. Gastroenterology 1964; 46: 543-549.

23. Bicks RO, Brown G, Hickey D, Rosenberg EW. Further observations on delayed hypersensitivity reaction in the guinea-pig colon. Gastroenterology $1965 ; 48$ : 425-429.

24. Bicks RO, Azar MM, Rosenberg EW, Dunham WG, Lunther JS. Delayed hypersensitivity reactions in the intestinal tract. I. Studies of 2,3 , dinitrochlorobenzene-caused guinea-pig and swine colon lesions. Gastroenterology 1967; 53: 422-436.

25. Rabin BS, Roger SJ. A cell-mediated model of inflammatory bowel disease in the rabbit. Gastroenterology 1978; 75: 29-33.
26. Bruce SR. Animal model of human disease: immunologic model of inflammatory bowel disease. Am J Pathol 1980; 99: 253-256.

27. Boxenbaum HG, Dairman W. Evaluation of an animal model for the screening of compounds potentially useful in human ulcerative colitis: effect of salicylazosulfapyridine and prednisolone on carrageenan-induced ulceration of the large intestine of the guinea pig. Drug Dev Ind Pharm 1977; 3 121-130.

28. Fielding JF. Dalziel's (Crohn's) disease: an historical review. History of Medicine 1972; 4: 20-23

29. Van Dijk APM, Wilson JHP, Zijlstra FJ. The effect of malotilate, a derivative of malotilate and a flavenoid on eicosanoid production in inflammatory bowel disease in rats. Mediators of Inflammation 1993; 2: 67-72.

30. Wallace JL. Release of platelet-activating factor (PAF) and accelerated healing induced by a PAF antagonist in an animal model of chronic colitis. Can J Physiol Pharmacol 1988; 66: 422-425.

31. Fiocchi C. Cytokines and animal models: a combined path to inflammatory bowel disease pathogenesis. Gastroenterology 1993; 104: 1202-1205.

32. Hawthorne AB, Boughton-Smith NK, Whittle BJR, Hawkey CJ. Colorectal leukotriene $\mathrm{B}_{4}$ synthesis in vitro in inflammatory bowel disease: inhibition by the selective 5-lipoxygenase inhibitor BWA4C. Gut 1992; 33: 513-517.

33. Pons L, Droy-Lefaix MT, Bueno L. Leukotriene $\mathrm{D}_{4}$ participates in colonic transit disturbances induced by intracolonic administration of trinitrobenzene sulfonic acid in rats. Gastroenterology 1992; 102: 149-156.

ACKNOWLEDGEMENT. The excellent technical assistance of Mr G. Haase is gratefully acknowledged.

\section{Received 30 June 1993: \\ accepted 12 August 1993}




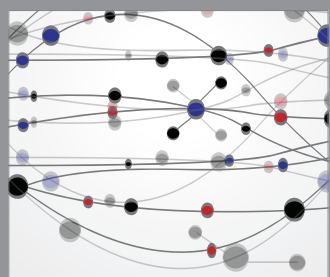

The Scientific World Journal
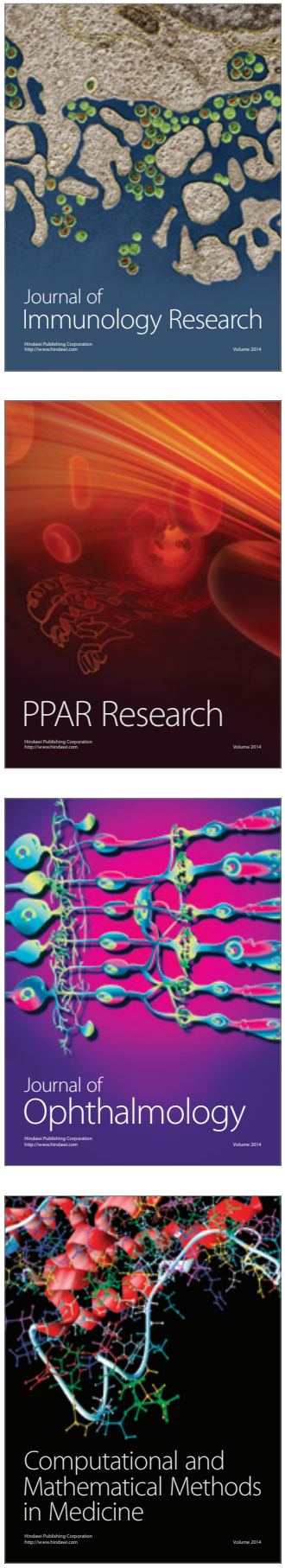

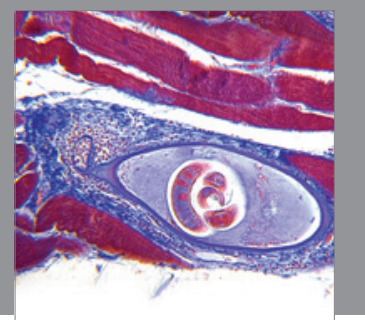

Gastroenterology

Research and Practice
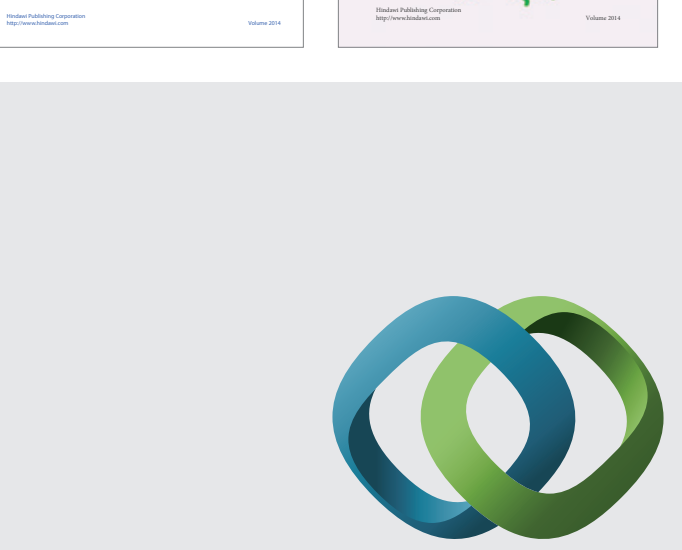

\section{Hindawi}

Submit your manuscripts at

http://www.hindawi.com
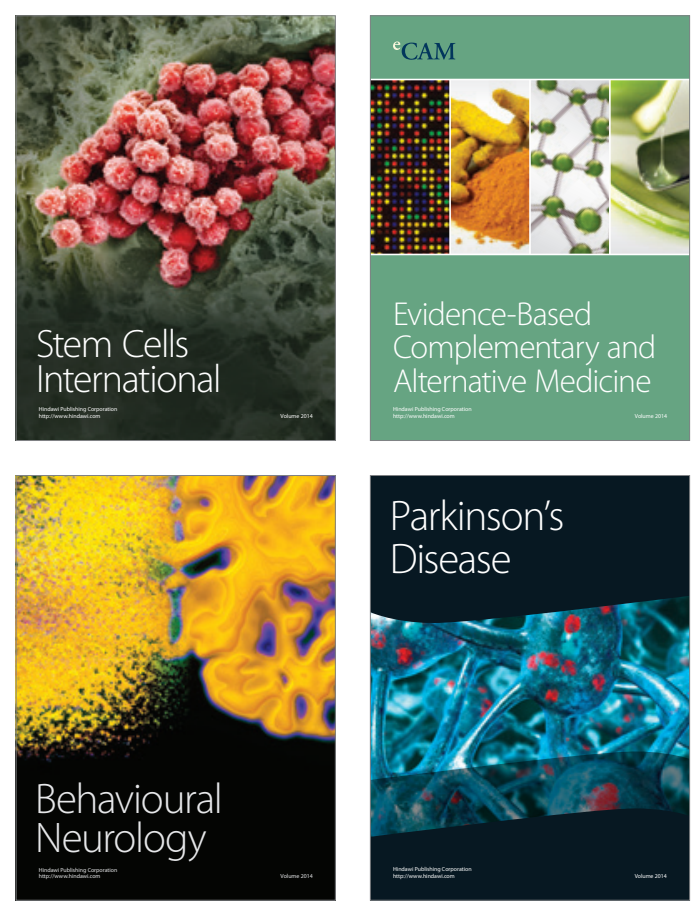

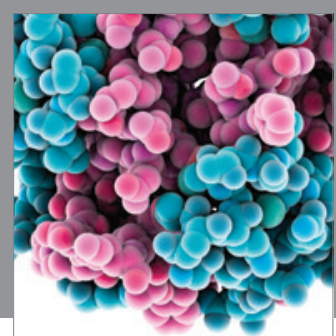

Journal of
Diabetes Research

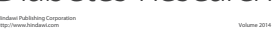

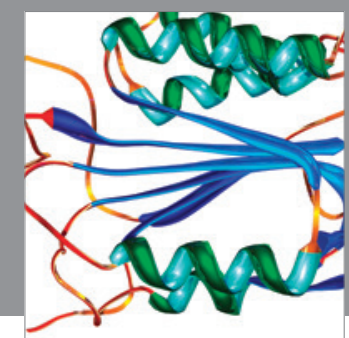

Disease Markers
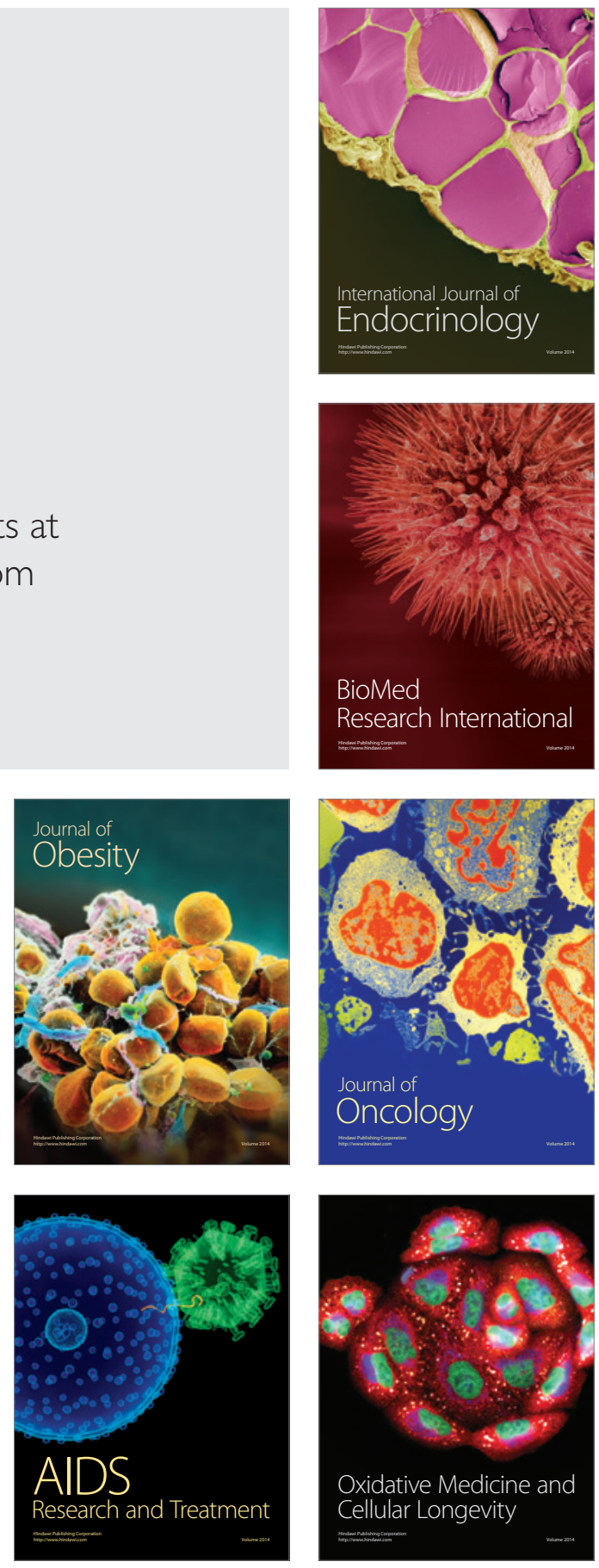